\title{
Do congressional candidates benefit from rejecting PAC contributions? Evidence from a pre-registered candidate evaluation survey experiment* $^{*}$
}

\author{
Nicholas R. Jenkins \\ University of California, Riverside
}

\author{
Michelangelo Landgrave \\ Princeton University
}

December 13, 2021

\begin{abstract}
Do congressional candidates benefit electorally from the public's disdain of political action committees (PACs)? Despite the large sums of money given by PACs, an increasing number of candidates have sworn off corporate PAC money. In this research note we investigate whether the decision to accept or reject PAC contributions in general affects voters' evaluation of candidates and their willingness to vote for them. To test these questions, we use a pre-registered candidate evaluation survey experiment that was fielded as part of the 2020 Cooperative Congressional Election Study. We find that voters are more likely to vote for, donate to, and trust candidates that reject PAC contributions. Surprisingly, we fail to find evidence that this effect is moderated by party ID. The evidence indicates that Republican and Democratic voters alike penalize candidates that accept PAC money. This study is among the first to investigate how candidates' campaign financing choices influence their perceptions among voters.
\end{abstract}

Key Words: Campaign Finance, Political Action Committees, Candidate Evaluations, Campaign Contribution Sources, Voter Perceptions

\footnotetext{
${ }^{*}$ Corresponding author: nicholas.jenkins@email.ucr.edu. Nicholas Jenkins is a doctoral candidate in the Department of Political Science at the University of California, Riverside. Michelangelo Landgrave is a Postdoctoral Research Associate in the Center for the Study of Democratic Politics and Department of Politics at Princeton University. We are grateful to Molly Ritchie and Todd Donovan for their feedback on earlier versions of this manuscript. All remaining errors are our own.
} 


\section{Introduction}

The American public disdains money in politics. When a 2017 Washington Post survey asked U.S. respondents what they saw as the primary cause of political dysfunction (Wagner and Clement 2017), the top two answers were money in politics and wealthy political donors. A similar survey in 2018 conducted by the Pew Research Center found that 74 percent of respondents believe that big donors have more political influence than other people (Jones 2018). Presumably in response to these public sentiments, candidates begun to distance themselves from political action committees (PACs), which are some of the largest sources of campaign contributions. In the 2020 election cycle, PACs contributed more than $\$ 582$ million dollars. A prominent example these distancing efforts is Senator Elizabeth Warren who, during her 2020 campaign, "swore off PAC money to make a statement" (Nilsen 2019). In an email to her supporters, Warren explained, "For every time you see a presidential candidate talking with voters at a town hall, rally, or local diner, those same candidates are spending three or four or five times as long with wealthy donors — on the phone, or in conference rooms at hedge fund offices, or at fancy receptions and intimate dinners all behind closed doors" (Nilsen 2019). Senator Warren was not alone in swearing off PAC money; 52 members of the 116th Congress refused corporate PAC money (Evers-Hillstrom 2018). In the 2020 elections, Democratic candidates were almost in competition with one another to distance themselves as far as they could from PACs and other moneyed special interests.

There are obvious costs to anti-PAC pledges, but are there larger benefits to be had? Are candidates who refuse PAC money rewarded electorally? We argue that anti-PAC pledges lead voters to perceive candidates as more trustworthy and thus be more likely to vote and donate to them. To test this claim, we fielded a pre-registered candidate evaluation survey experiment as part of the 2020 Cooperative Congressional Election Study (CCES). Survey respondents were presented with a description of a hypothetical co-partisan congressional candidate where we experimentally manipulated the candidates' attributes, with our 
attribute of interest being whether a candidate explicit states they accept or reject PAC contributions. We find that voters, regardless of political party, are more likely to trust, vote for, and donate to congressional candidates who reject PAC money than they are for candidates who accept PAC money. This study contributes to a growing and nascent literature on how the sources of a candidate's campaign financing influences voters' evaluation of candidates (Bowler and Donovan 2016; Dowling, Miller, and Miller 2014; Riggs 2017).

\section{Money in Politics}

Previous research has investigated the role of money in politics and campaigns from many different perspectives. Scholars have examined the (in)ability of campaign finance legislation and the Federal Election Commission (FEC) to limit the undue influence of large donors (Magleby and Nelson 2010; Raja 2008), why donors donate (Barber, Canes-Wrone, and Thrower 2017), to what extent their donations increase access to politicians (Kalla and Broockman 2016; Jenkins, Landgrave, and Martinez 2020), and what their donation strategies are (Francia et al. 2003). Researchers, however, have also investigated questions related to how individuals perceive money in politics. For example, in 20162016 Shaun Bowler and Todd Donovan investigated how different sources of campaign finance affect voter's perceptions of corruption. Using a survey experiment, they find that beliefs about whether any particular contribution is corrupt dependents on an individual's partisanship and the information they have about where the contribution came from. Their findings indicate that voters care about where campaign contributions come from and that messages about campaign finance may alter how they perceive candidates. By announcing opposition to PAC contributions, candidates may provide an information signal to voters that PAC contributions produce adverse representational effects and that pursuing campaign financing through alternative means, such as small donations from the general public, is a more "ethical" strategy. This strategy may be particularly effective for candidates refusing corporate 
PAC money since voters believe that contributions to candidates from corporations are more corrupt than contributions from individuals (Bowler and Donovan 2016). Based on these findings, we argue that candidates who refuse PAC money should be evaluated more favorably by voters. Specifically we argue that candidates that reject PAC money will be seen as more trustworthy than candidates who accept PAC money.

Since, congressional candidates are competing to serve as the public's agents, trust is an essential part of the principal-agent relationship between voters and their representatives (Lupia and McCubbins 1998). Candidates who accept PAC money are plausibly seen as less trustworthy and less likely to carry out the public's (the principal's) preferred agenda because voters believe them to be beholden to PAC contributors ${ }^{1}$ Given this, candidates may be able to strategically advertise that they will not accept PAC contributions in order to prime voters to think they are more trustworthy. This leads to our first hypothesis:

Hypothesis 1 Respondents will perceive a candidate who rejects PAC contributions as more trustworthy than a candidate who accepts PAC contributions.

Candidates perceived as trustworthy are desirable to voters because of, as discussed above, the principal-agent relationship between constituents and their representatives. Voters believe that a trustworthy candidate is more likely to carry out their policy preferences in office as opposed to the preferences of third parties, like campaign donors. If voters believe candidates who reject PAC contributions are more trustworthy and that trustworthy candidates are more likely to execute their preferred policy preferences, then voters should also be more likely to vote for these candidates. Thus, we also hypothesize that voters will be more willing to vote for candidates who reject PAC contributions than they are for candidates who accept PAC money. This expectation is consistent with extant evidence on the role of trust on vote choice (Hetherington 1999; Parker 1989). This is our second hypothesis:

\footnotetext{
${ }^{1}$ Emphasize on "believe." It is possible that PACs and other interest groups serve to increase the public's control over representatives. Nonetheless, the public may also perceive that PACs decrease their control over representatives.
} 
Hypothesis 2 Respondents will be more likely to vote for a candidate who rejects PAC contributions than a candidate who accepts PAC contributions.

Campaigns, however, are extraordinarily expensive, and rejecting contributions from large donors means that candidates will need to replace these funds with those from other sources. The most commonly discussed substitution among candidates who refuse PAC money is small-dollar donations. Candidates like Senator Bernie Sanders advertise the fact that they do not accept PAC money while aggressively soliciting small individual donations. Throughout his campaign, Senator Sanders proudly emphasized that the average donation made to his campaign in 2020 was twenty-seven dollars (Gambino 2019). This strategy is not only meant to galvanize supporters to donate, but since voters perceive small-dollar donations from individuals as more honest (Bowler and Donovan 2016), it also creates an image of trustworthiness. Whether candidates can raise enough money from small-donors to replace PAC money is unclear. Ella Nilsen (2019) called Senator Elizabeth Warren's more extreme strategy of saying no to, “... PAC[s], corporate PAC[s], or Super PAC money, [and] no donations from federal lobbyists" a "risky move." Unless there is a more covert strategy in making an anti-PAC pledge, these candidates seem to hope that their public stances against large-dollar donations will excite their supporters enough to have them donate to their campaigns. This leads to our third hypothesis:

Hypothesis 3 Respondents will be more likely to donate to a candidate who rejects PAC contributions than a candidate who accepts PAC contributions.

Finally, the fact that anti-PAC pledges are concentrated among Democratic candidates suggests that Democrats specifically expect this strategy to be popular with their supporters (Evers-Hillstrom 2018; Lerer 2018; Fischer 2019). During the 116th Congress, 52 Democratic members of Congress (MCs) refused contributions from PACs during their campaigns while only 2 Republican MCs refused PAC money during the same cycle (Evers-Hillstrom 2018). This trend continued in the 2020 election cycle with 44 candidates (43 Democrats and 1 
Republican) refusing PAC money (Baumgart 2019). The concentration of pledges to refuse PAC contributions among Democratic candidates seems to be an attempt to galvanize Democratic voters who may be more troubled by money in politics than Republicans. Numerous surveys find that Democrats are more supportive of campaign finance reform than Republicans. According to Pew Research Center (2015), 85 percent of Democrats and 71 percent of Republicans believe there should be spending limits for individuals and organizations. When asked if wealthy donors do not have more influence than others, 50 percent of Democrats said this is not an accurate description compared to 35 percent of Republicans - a gap of 15 percentage points. This leads to our final hypothesis:

Hypothesis 4 Democratic respondents will be more likely than Republican respondents to vote for, trust, and donate to a candidate who rejects corporate PAC money.

\section{Data and Methods}

To evaluate these hypotheses, we fielded a candidate evaluation survey experiment in the 2020 CCES ${ }^{2}$ Respondents were presented with a hypothetical congressional candidate in a primary election from the respondent's political party. Independents were randomly asked about a Republican or Democratic primary. We experimentally randomized the candidate's prior political experience, gender, and whether they accept or reject PAC contributions. Our manipulation of interest is whether candidates accept or reject PAC contributions. Figure 4 in Appendix $\mathrm{A}$ shows how the conjoint design was implemented in the CCES ${ }^{3}$ After reading the randomized description of the candidate, respondents were asked to rate how likely they are to vote for, donate to, and trust the candidate on a 7-point scale. With these data, we estimate the effects of refusing PAC contributions on respondent perceptions using ordinal logistic regression models estimated within a Bayesian framework. All analyses use four

\footnotetext{
${ }^{2}$ We conducted a pilot in the Spring of 2020 with undergraduate students at the University of California, Riverside and Los Angeles. See Appendix B for more information on the pilot study.

${ }^{3}$ This experiment received IRB approval and was pre-registered on September 10, 2020. The preregistration is not linked here to maintain the anonymity of the author(s).
} 
Markov chain Monte Carlo (MCMC) chains at 4,000 iterations each with a warmup period of 1,000 samples using the Hamiltonian Monte Carlo algorithm. All chains of all models indicated convergence with every $\hat{R}$ value being less than 1.01.

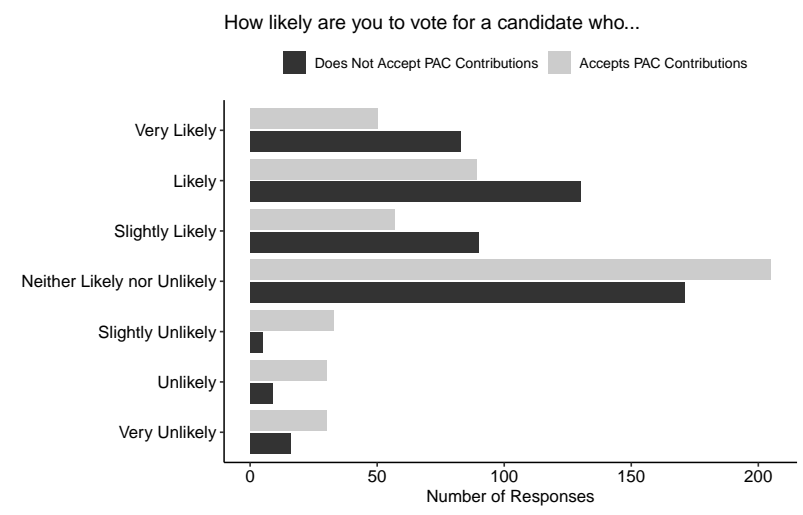

(a) PAC Position and Voting Likelihood

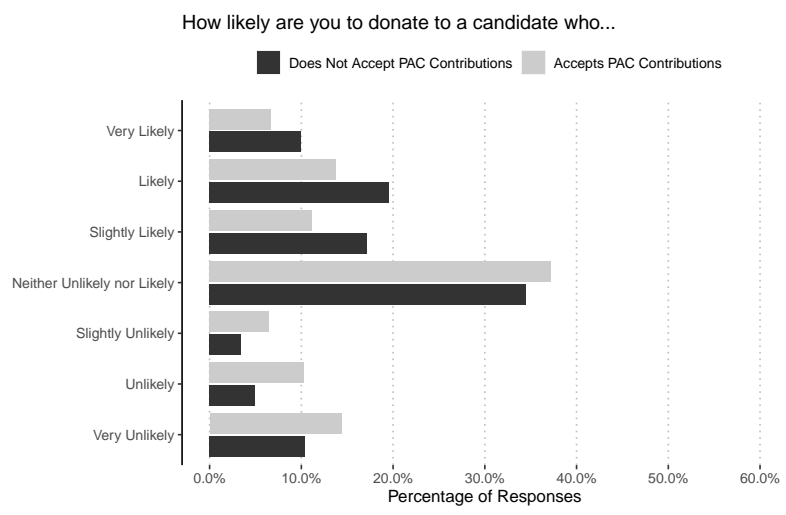

(b) PAC Position and Likelihood of Donating

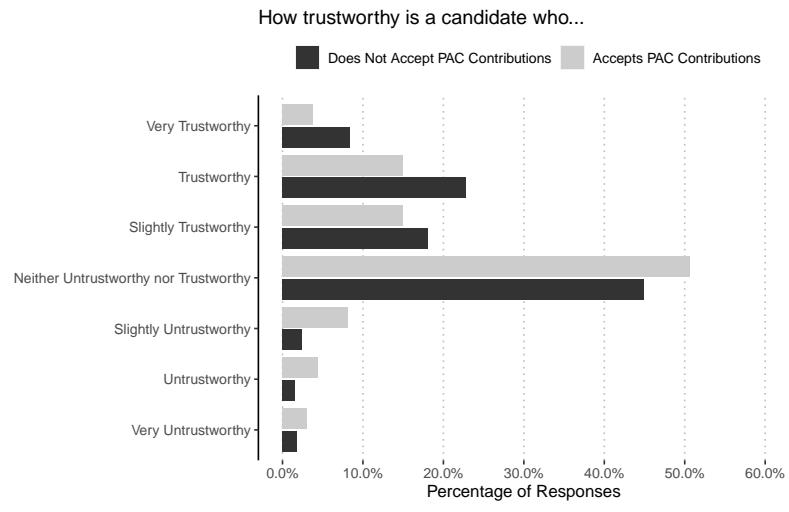

(c) PAC Position and Trustworthiness

Figure 1: CCES Respondent Answers. This figures show that respondents are more say that they would vote for, donate to, and trust candidates who do not accept corporate PAC contributions.

A total of 998 CCES respondents completed our study. In the sample, there are 220 Republicans, 334 Democrats, and 258 Independents. ${ }^{4}$ Figure 1 summarizes the responses of all CCES participants for each question. Our expectations hold on both ends of each scale. Respondents report being more likely to vote for, donate to, and trust candidates who do not accept PAC contributions. Moreover, respondents report more answers on the negative

\footnotetext{
${ }^{4}$ This sample size reflects budgetary restraints.
} 
end of the scale for candidates who accept PAC contributions: $5^{5}$

\section{Results}

The results of the three ordinal logistic regression models are summarized in Figure 2. The experiment provides strong evidence in support of our first three hypotheses. Candidates that refuse PAC contributions are predicted to see a 67 percent increase in the relative probability of trusting the candidate (median log-odds estimate $=0.723,95 \% \mathrm{HDI}[0.485$, 0.957]), an approximate 69 percent increase in the relative probability of favorable opinions towards voting for the candidate (median log-odds estimate $=0.805,95 \% \operatorname{HDI}[0.567,1.03]$ ), and a 64 percent increase in the relative probability of favorable opinions towards donating to the candidate (median log-odds estimate $=0.579,95 \% \mathrm{HDI}[0.355,0.802])$.

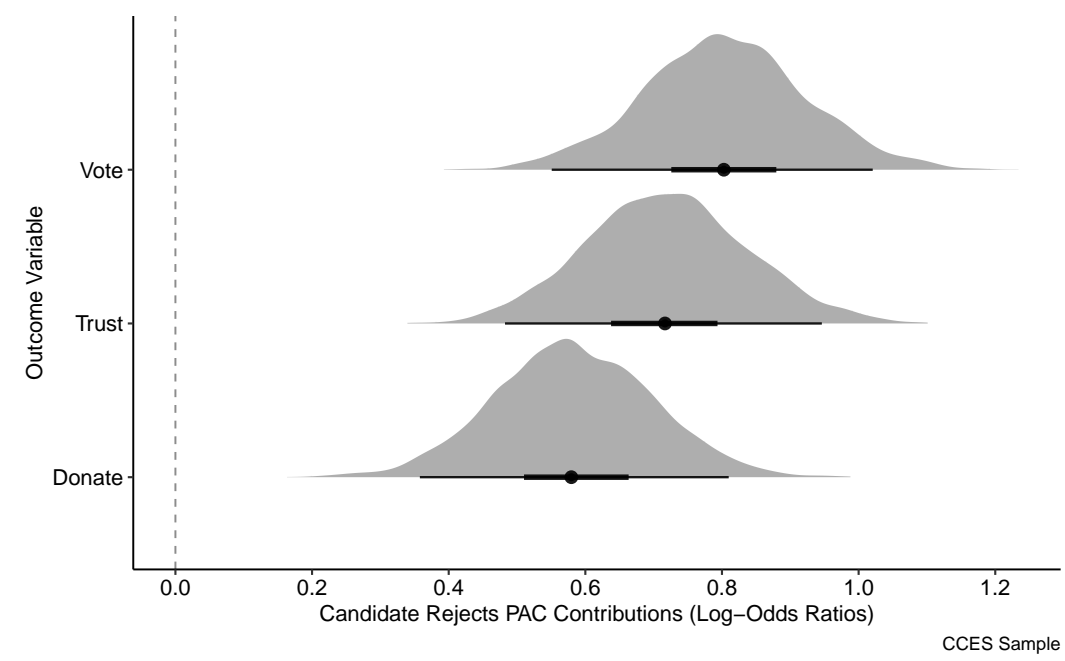

Figure 2: The Effects of Refusing PAC Contributions on Voter Perceptions of a Candidate. Respondents are more willing to vote for, donate to, and trust candidates that do not accept PAC contributions. The point represents the median point estimate, the thick bar indicates the 50 percent highest density interval, and the thin bar represents the 95 percent highest density interval.

These findings show that the average voter electorally rewards candidates who accept PAC contributions, views a candidate who rejects PAC contributions as more trustworthy,

\footnotetext{
${ }^{5}$ These patterns are similar to the results of the pilot study shown in Figure 6 of Appendix $B$.
} 
and is more likely to donate to these candidates. These results suggest that candidates can eschew PAC contributions in exchange for greater electoral support and donations from the average voter even though the total dollar amount of contributions may not be exceed the amount raised by PAC accepting candidates. Candidates who reject PAC contributions are also rated as more trustworthy than candidates who accept PAC money. This increased trustworthiness translates to an increase in the likelihood of being voted for and an increase in the likelihood of receiving a donation. The former is intrinsically important in electoral politics. The latter, an increase in donations, suggests that candidates may be able to substitute financial support from PACs with donations from small-dollar donors. Future research should attempt to estimate how much candidates can raise by rejecting PAC money and whether or not PAC contributions can be effectively substituted with small-dollar donations.

Finally, we test our fourth hypothesis that the effects of refusing PAC contributions will be stronger for Democrats. As shown in Figure 3, we fail to find any strong evidence of a party moderation effect. Republican and Democratic voters alike seem to be equally likely to penalize candidates that accept PAC contributions. This is a surprising finding because most candidates who have rejected PAC contributions are Democrats. Only a handful of Republican candidates have rejected PAC money. Additional research is needed to understand why Democratic candidates are more likely to reject PAC contributions despite both Democratic and Republican respondents preferring candidates who reject PAC contributions. 


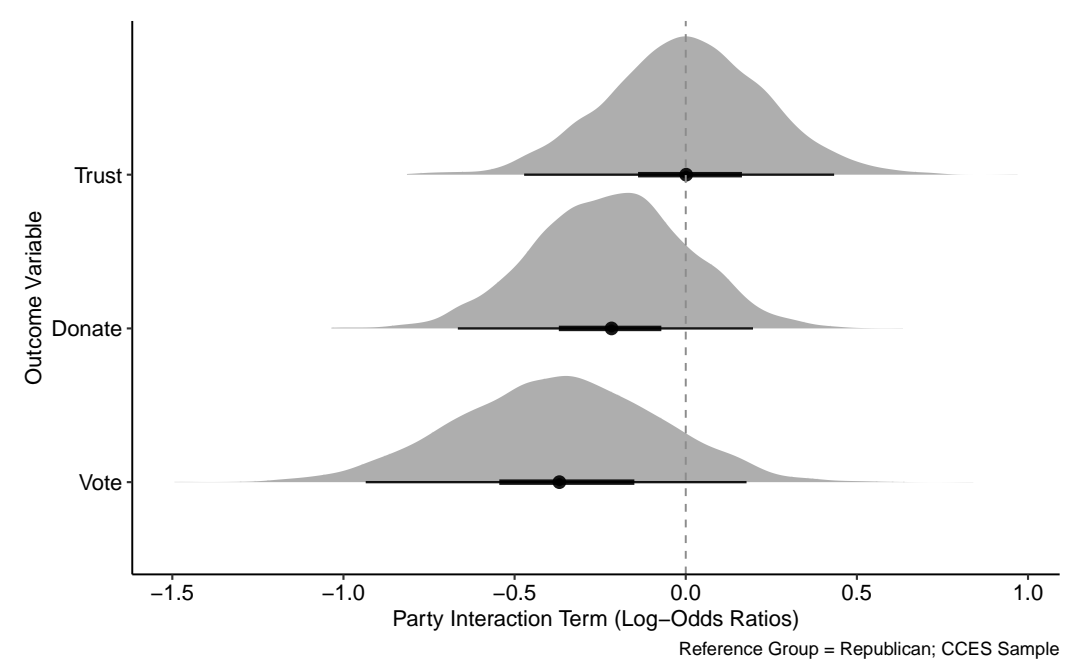

Figure 3: The Effects of Refusing PAC Contributions on Voter Perceptions of Candidates Moderated by Party ID. These figures show that both Democrats and Republicans evaluate candidates who refuse PAC contributions similarly. The point represents the median point estimate, the thick bar indicates the 50 percent highest density interval, and the thin bar represents the 95 percent highest density interval.

\section{Conclusion}

Political action committees are a prominent facet of American electoral politics, but voters' disdain for wealthy donors may present candidates with electoral opportunities. Using a conjoint survey experiment fielded in the CCES, we find that voters perceive candidates who refuse PAC contributions as more trustworthy than candidates who accept PAC contributions and that voters are more likely to both vote for and donate to them. These results contribute to a growing literature on voters' reactions to campaign financing. They also help us better understand why some candidates may choose to reject PAC contributions. We fail, however, to find evidence of a partisan divide - both Democratic and Republican respondents favored candidates that reject PAC campaign contributions. This suggests that the partisan divide among candidates regarding PAC contributions is driven by factors beyond voter attitudes towards money in politics. 


\section{References}

Barber, Michael J., Brandice Canes-Wrone, and Sharece Thrower. 2017. "Ideologically Sophisticated Donors: Which Candidates Do Individual Contributors Finance?" American Journal of Political Science 61 (2): 271-288.

Baumgart, Alex. 2019. Opensecrets.org No Corp PAC Members.

Bowler, Shaun, and Todd Donovan. 2016. "Campaign Money, Congress, and Perceptions of Corruption". American Politics Research 44 (2): 272-295.

Dowling, Conor M., Michael G. Miller, and Michael G. Miller. 2014. Super PAC! : Money, Elections, and Voters after Citizens United. Routledge.

Druckman, James N., and Cindy D. Kam. 2011. "Students as Experimental Participants: A Defense of the 'Narrow Data Base'". In Cambridge handbook of experimental political science, 1:41-57. Cambridge University Press.

Evers-Hillstrom, Karl. 2018. "Democrats are rejecting corporate PACs: Does it mean anything?" OpenSecrets News ().

Fischer, Brendan. 2019. "No PAC Money Pledges Are in, But That Doesn't Mean Big Money is Out: Understanding the No PAC Pledges". Campaign Legal Center Advancing Democracy Through Law ().

Francia, Peter L., et al. 2003. The Financiers of Congressional Elections: Investors, Ideologues, and Intimates. Columbia University Press.

Gambino, Lauren. 2019. "'Not the billionaires': why small-dollar donors are Democrats' new powerhouse". The Guardian ().

Hetherington, Marc J. 1999. "The effect of political trust on the presidential vote, 1968-96". American Political Science Review 93 (2): 311-326. 
Jenkins, Nicholas R., Michelangelo Landgrave, and Gabriel E. Martinez. 2020. "Do campaign contributions facilitate access to government information? Evidence from a FOIA compliance field experiment with US municipalities". Journal of Behavioral Public Administration 3, no. 2 ().

Jones, Bradley. 2018. "Most Americans want to limit campaign spending, say big donors have greater political influence". Pew Research Center ().

Kalla, Joshua L., and David E. Broockman. 2016. "Campaign Contributions Facilitate Access to Congressional Officials: A Randomized Field Experiment" [inlangen]. American Journal of Political Science 60, no. 3 (): 545-558.

Lerer, Lisa. 2018. "Corporate donations are new test for Democratic candidates". Associated Press ().

Lupia, Arthur, and Mathew D. McCubbins. 1998. The democratic dilemma: can citizens learn what they need to know? Political economy of institutions and decisions. Cambridge, U.K. ; New York: Cambridge University Press.

Magleby, David B., and Candice J. Nelson. 2010. The Money Chase: Congressional Campaign Finance Reform. Brookings Institution Press.

Nilsen, Ella. 2019. "In the race for grassroots donations, it's a battle between Elizabeth Warren and Bernie Sanders". Vox ().

Parker, Glenn R. 1989. "The role of constituent trust in congressional elections". Public Opinion Quarterly 53 (2): 175-196.

Pew Research Center. 2015. Beyond Distrust: How Americans View Their Government.

Raja, Raymond J. La. 2008. Small Change: Money, Political Parties, and Campaign Finance Reform. University of Michigan Press. 
Riggs, Tara S. 2017. "Using Experimental Design to Test the Effect of Campaign Donation Knowledge on Interpersonal Political Trust in the United States". PhD thesis, Central European University.

Wagner, Josh, and Scott Clement. 2017. "It's just messed up': Most think political divisions as bad as Vietnam era, new poll shows". The Washington Post (). 


\title{
Appendix A Conjoint Design
}

\author{
Below is a hypothetical candidate running in a [R's PARTY ID]'s primary elec- \\ tion for Congress. \\ Candidate Profile: \\ Prior Elected Office Randomized - See Below \\ Campaign Contribution Position Randomized - See Below \\ Gender $\quad$ Randomized - See Below \\ [RANDOMIZE] Prior Elected Office: \\ 1. No Prior Experience in Elected Office \\ 2. Previously Elected Councilmember \\ 3. Previously Elected Mayor \\ [RANDOMIZE] Campaign Contribution Position \\ 1. Campaign Doesn't Accept Contributions from Political Action Committees \\ 2. Campaign Accepts Contributions from Political Action Committees \\ [RANDOMIZE] Gender \\ 1. Male \\ 2. Female
}

Based on the presented information, answer the following questions:

1. How likely are you to vote for the candidate?

2. How likely are you to donate to the candidate?

3. How trustworthy do you think the candidate is?

Answer choices for questions:

1. Very Likely/Very Trustworthy

2. Likely/Trustworthy

3. Slightly Likely/Slightly Trustworthy

4. Neither Unlikely nor Likely/Neither Untrustworthy nor Trustworthy

5. Slightly Unlikely/Slightly Trustworthy

6. Unlikely/Untrustworthy

7. Very Unlikely/Very Untrustworthy

Figure 4: Conjoint Design in the Cooperative Congressional Election Survey 


\section{Appendix B Pilot Study}

\section{B.1 Data and Methods}

As an initial test of our hypotheses, we conducted a pilot study with undergraduate students at two large west coast state universities ${ }^{6}$ Students in the pilot took part in a candidate evaluation survey experiment. Students were presented with a hypothetical candidate running in their party's Congressional primary.7 The pilot study randomized the candidate's race, previous political experience, and whether or not PAC contributions are accepted for a hypothetical candidate running for office. After reading the candidate's randomized description, respondents were asked to rate how likely there were to vote for, donate to, and trust the candidate on a 7 -point scale 8 Figure 5 shows the conjoint design.

Figure 6 shows the responses of all 390 respondents for each outcome variable: voting likelihood, donating likelihood, and trustworthiness. In general, the patterns are consistent with our hypotheses. For example, when asked how likely they would be to vote for a candidate, Panel (a) shows that respondents answered "very likely", "likely," and "slightly likely" at higher rates when the candidate does not accept PAC contributions. Similarly, respondents more frequently reported that they would be "slightly unlikely," "unlikely," and "very unlikely" to vote for a candidate that accepts PAC contributions. These same patterns hold for candidate trustworthiness, as shown in Panel (c).

Patterns in donation likelihood are slightly more difficult to identify in Panel (b). While answers of "very likely," "likely," and "slightly likely" are consistent with our hypotheses, patterns on the other side of the scale are not. For example, respondents more frequently reported that they would be "slightly unlikely" and "unlikely" to donate to a candidate that does not accept PAC contributions than they would to a candidate that accepts PAC contributions.

\footnotetext{
${ }^{6}$ See Druckman and Kam $\left.\sqrt{2011}\right)$ for more details on using undergraduates in survey experiments.

${ }^{7}$ Independents were randomly asked about either a Republican or Democratic primary.

${ }^{8}$ This initial study received IRB approval but was not pre-registered.
} 
We use ordinal logistic regression to estimate the effects of refusing PAC contributions on our outcomes of interest: reported vote choice, donation choice, and perceived trustworthiness. Finally, each model is estimated within a Bayesian framework to avoid assumptions about sampling distributions and to interpret coefficients in a probabilistic fashion rather than relying on p-values.

\section{B.2 Results}

Figure 7 shows the results of our first three hypotheses, that voters will be more likely to vote for, donate to, and trust candidates who do not accept PAC contributions. Specifically, for candidates that refuse PAC contributions, the model predicts roughly a 60 percent increase in the relative probability of favorable opinions towards voting for the candidate (median log-odds estimate $=0.418,95 \% \mathrm{HDI}[0.060,0.756])$ a 58 percent increase in the relative probability of favorable opinions towards donating to the candidate (median log-odds estimate $=$ $0.339,95 \% \operatorname{HDI}[0.004,0.696])$ and a 65 percent increase in the relative probability of favorable opinions on trusting the candidate (median log-odds estimate $=0.625,95 \%$ HDI $[0.227$, $0.999])$.

Although we find support for our first three hypotheses in the undergraduate sample, this sample has some limitations. Namely, the undergraduate respondents were overwhelmingly Democrats (316 out of 390 respondents), hindering our ability to test for partisan moderation. We fielded a similar candidate evaluation survey experiment in the 2020 Cooperative Congressional Election Study (CCES) to address these limitations. 
Below is a hypothetical candidate running in a party primary election for Congress. Based on the presented information, answer the following questions.

Candidate Profile:

\begin{tabular}{ll}
\hline Prior Elected Office & Randomized - See Below \\
Campaign Contribution Position & Randomized - See Below \\
Race/Nationality & Randomized - See Below
\end{tabular}

[RANDOMIZE] Prior Elected Office:

1. No prior experience in elected office

2. Previously Elected Councilmember

3. Previously Elected Mayor

[RANDOMIZE] Campaign Contribution Position

1. Campaign Doesn't Accept Contributions from Political Action Committees

2. Campaign Accepts Contributions from Political Action Committees

[RANDOMIZE] Race/Nationality

1. White

2. Mexican American

3. Salvadoran American

4. Chinese American

5. Vietnamese American

Based on the presented information, answer the following questions:

1. On a scale of 1 to 7 , with 7 being very likely and 1 being very unlikely, how likely are you to vote for the candidate?

2. On a scale of 1 to 7 , with 7 being very likely and 1 being very unlikely, how likely are you to donate to the candidate?

3. On a scale of 1 to 7 , with 7 being very trustworthy and 1 being not at all trustworthy, how trustworthy do you think the candidate is?

Answer choices for questions:

1. Very Unlikely/Very Untrustworthy

2. Unlikely/Untrustworthy

3. Slightly Unlikely/Slightly Trustworthy

4. Neither Unlikely nor Likely/Neither Untrustworthy nor Trustworthy

5. Slightly Likely/Slightly Trustworthy

6. Likely/Trustworthy

7. Very Likely/Very Trustworthy

Figure 5: Conjoint Design in the Pilot Study 


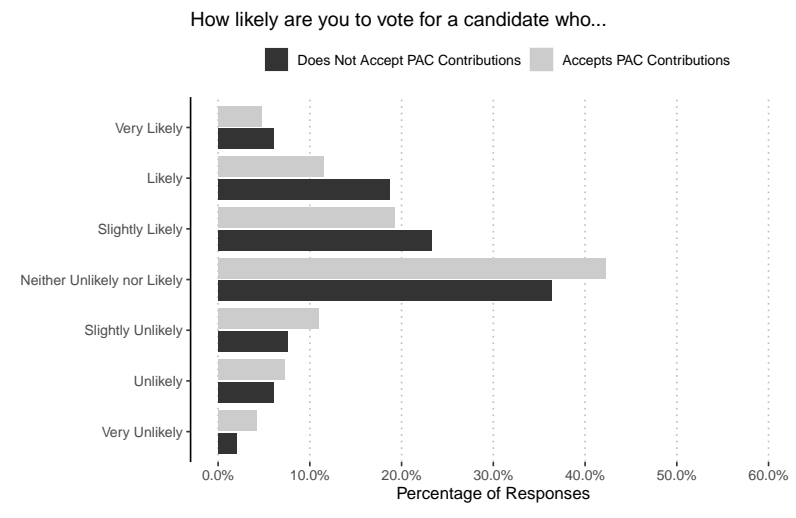

(a) PAC Position and Voting Likelihood

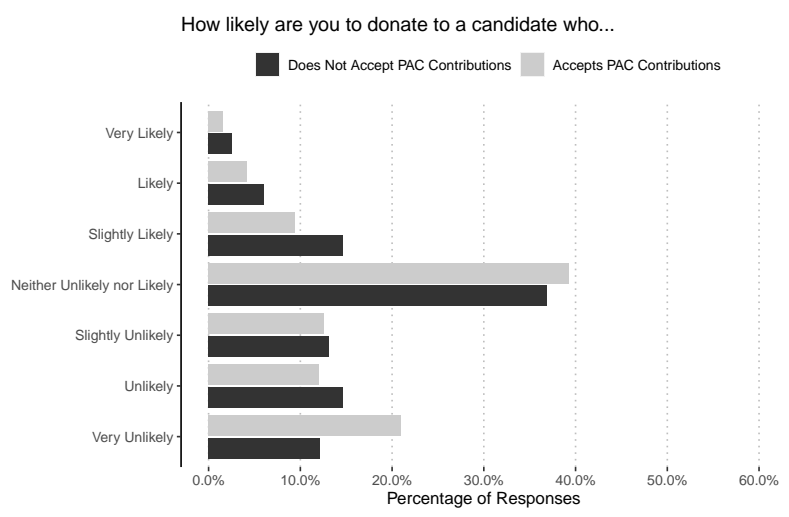

(b) PAC Position and Likelihood of Donating

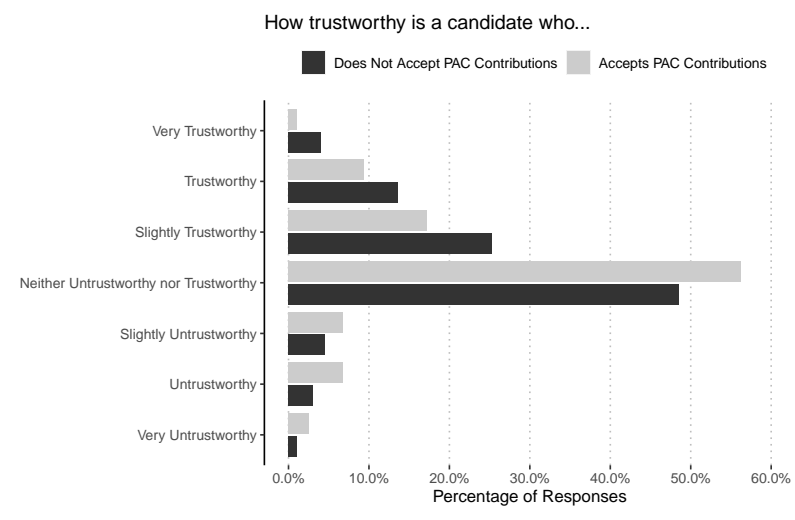

(c) PAC Position and Trustworthiness

Figure 6: Pilot Study Respondent Answers. This figures show that respondents are more say that they would vote for, donate to, and trust candidates who do not accept corporate PAC contributions. 


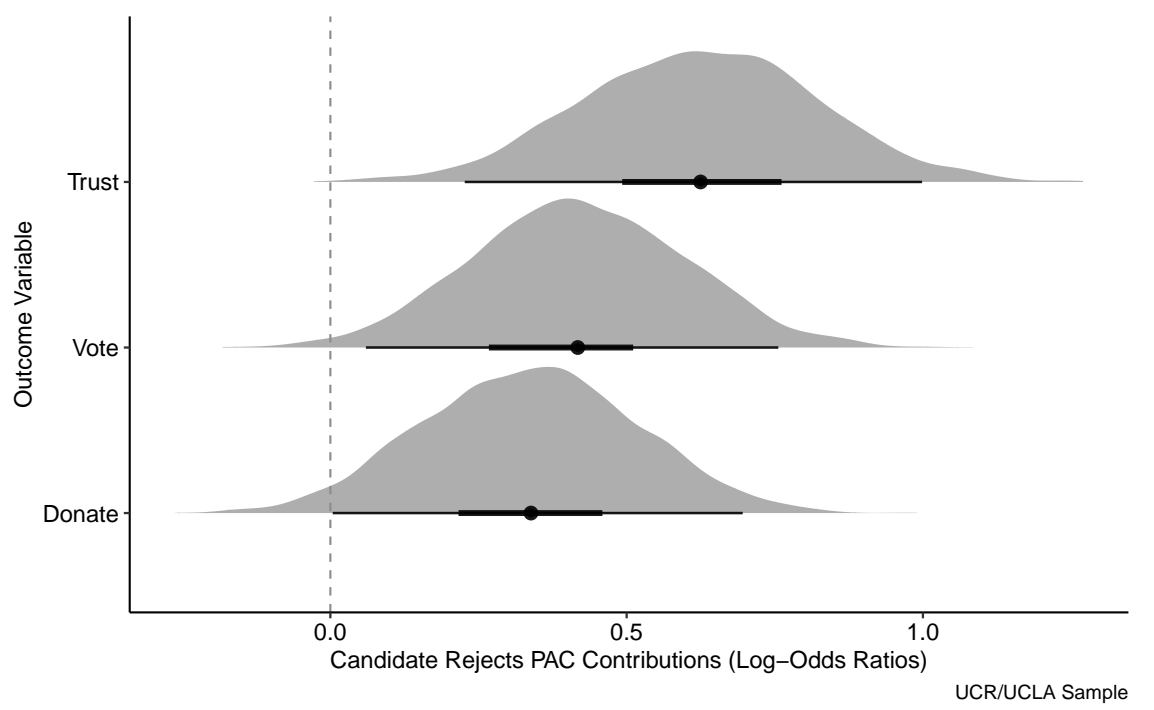

Figure 7: The Effects of Refusing PAC Contributions on Voter Perceptions of a Candidate. Respondents are more willing to vote for, donate to, and trust candidates that do not accept PAC contributions. The point represents the median point estimate, the thick bar indicates the 50 percent highest density interval, and the thin bar represents the 95 percent highest density interval. Analyses use four Markov chain Monte Carlo (MCMC) chains at 4,000 iterations each with a warmup period of 1,000 samples using the Hamiltonian Monte Carlo algorithm. All chains indicate convergence, with every $\hat{R}$ value being less than 1.01 . 